АНАЛИЗ СТОИМОСТИ БОЛЕЗНИ САХАРНОГО ДИАБЕТА 2 ТИПА

В РОССИЙСКОЙ ФЕДЕРАЦИИ: РЕЗУЛЬТАТЫ РОССИЙСКОГО МНОГОЦЕНТРОВОГО

НАБЛЮДАТЕЛЬНОГО ФАРМАКОЭПИДЕМИОЛОГИЧЕСКОГО ИССЛЕДОВАНИЯ

ФОРСАЙТ-СД2

() И.И. Дедов ${ }^{1}$, М.Ф. Калашникова ${ }^{2}$, Д.Ю. Белоусов ${ }^{3}$, А.С. Колбин ${ }^{4}$, В.В. Рафальский5,6, А.Е. Чеберда ${ }^{3}$, М.А. Кантемирова7, В.Д. Закиев ${ }^{2}$ В.В. Фадеев²

'ФГБУ Национальный медицинский исследовательский центр эндокринологии Минздрава России, Москва ${ }^{2}$ ФГАОУ ВО Первый Московский государственный медицинский университет имени И.М. Сеченова Минздрава России (Сеченовский Университет), Москва

${ }^{3}$ ООО Центр фармакоэкономических исследований, Москва

${ }^{4}$ ФГБОУ ВО Первый Санкт-Петербургский государственный медицинский университет им. акад. И.П. Павлова, Санкт-Петербург

5ФГБОУ ВО Смоленский государственный медицинский университет Минздрава России, Смоленск ${ }^{6}$ ФГАОУ ВПО Балтийский федеральный университет имени И. Канта, Калининград

7ГБУЗ Городская клиническая больница им. С.П. Боткина, Москва

ОБОСНОВАНИЕ. Анализ стоимости болезни является основой для принятия решений о распределении финансовых ресурсов при оказании специализированной медицинской помощи в современной системе здравоохранения. Учитывая широкую распространенность сахарного диабета 2 типа (СД2), актуальной задачей является расчет общих (прямых и непрямых) затрат на лечение данного заболеванияв Российской Федерации (РФ).

ЦЕЛЬ. Провести анализ болезни с учетом общих затрат на лечение СД2 в зависимости от наличия осложнений и сопутствующих заболеваний.

МАТЕРИАЛЫ И МЕТОДЫ. Расчет общих затрат на лечение СД2 проведен на основании данных, полученных в Российском многоцентровом наблюдательном исследовании «ФармакОэпидемиологические и клинико-экономические аспекты совеРшенСтвовАния организации медицинскоЙ помощи больным Сахарным Диабетом 2 Типа в Российской Федерации (ФОРСАЙТ-СД2)». Информация о каждом пациенте была получена из первичной медицинской документации и при анкетировании пациентов. Общие затраты рассчитывались как сумма прямых медицинских затрат, прямых немедицинских затрат и непрямых затрат.

РЕЗУЛЬТАТЫ. В окончательный анализ включены 2014 больных СД2 из 45 городов РФ. Общие прямые медицинские затраты на лечение СД2, его осложнений и сопутствующих заболеваний на 1 пациента в год составили 105337 руб. (\$2742), прямые немедицинские затраты - 24518 руб. (\$638), а непрямые затраты - 149754 руб. (\$3898). Общая стоимость лечения СД2 в РФ в 2014 г. составила 279609 руб. (\$7278) на 1 пациента в год.

ЗАКЛюЧЕНИЕ. Большую часть затрат (53,5\%) составляют потери Внутреннего валового продукта (ВВП) вследствие нетрудоспособности пациентов. Прямые медицинские затраты составляют 37,7\% от общей стоимости болезни, из которых 57\% приходится на лечение осложнений СД и сопутствующих заболеваний, тогда как на долю сахароснижающей терапии - всего $10 \%$.

КЛЮЧЕВЫЕ СЛОВА: сахарный диабет 2 типа; фармакоэпидемиология; анализ; стоимость болезни; прямые медицинские затраты; прямые немедицинские затраты; непрямые затраты

\title{
COST-OF-ILLNESS ANALYSIS OF TYPE 2 DIABETES MELLITUS IN THE RUSSIAN FEDERATION: RESULTS FROM RUSSIAN MULTICENTER OBSERVATIONAL PHARMACOEPIDEMIOLOGIC STUDY OF DIABETES CARE FOR PATIENTS WITH TYPE 2 DIABETES MELLITUS (FORSIGHT-T2DM)
}

(c) Ivan I. Dedov', Marina F. Kalashnikova², Dmitriy Y. Belousov³, Aleksei S. Kolbin'4, Vladimyr V. Rafalskiy ${ }^{5,6}$, Alexei E. Cheberda ${ }^{3}$, Maria A. Kantemirova ${ }^{7}$, Vadim D. Zakiev², Valentin V. Fadeyev²

'Endocrinology Research Centre, Moscow, Russia

${ }^{2}$ Sechenov First Moscow State Medical University, Moscow, Russia

${ }^{3}$ Center of Pharmacoeconomics and Outcomes Research, Moscow, Russia

${ }^{4}$ Pavlov First St. Petersburg State Medical University, St. Peterburg, Russia

${ }^{5}$ Smolensk State Medical University, Smolensk, Russia

${ }^{6}$ Immanuel Kant Baltic Federal University, Kaliningrad, Russia

${ }^{7}$ City clinical hospital of S. P. Botkin, Moscow, Russia 
BACKGROUND: Cost-of-Illness Analysis (COI) constitutes the basis for the decision-making process on the budget and allocation in a modern health care system. Considering the wide prevalence of type 2 diabetes mellitus (T2DM), it is important to perform COI in the Russian Federation (RF).

AIM: The aim of the secondary objective FORSIGHT-T2DM study was to conduct Cost-of-Illness Analysis (COI) of T2DM in the Russian Federation in relation to taking into consideration the presence of complications and concomitant diseases.

MATERIALS AND METHODS: COI of T2DM was performed using the data obtained in Russian multicenter observational, pharmacoepidemiologic cross-sectional study of diabetes care for assessing routine healthcare pattern of T2DM in the Russian Federation (FORSIGHT-T2DM). Information for each patient was collected from primary medical records and By asking patients to fill out a questionnaire. Total costs were calculated as the sum of direct medical costs (DCm), direct non-medical costs (DCn) and indirect costs (IC).

RESULTS: The final analysis included data from 2014 patients with T2DM residing in 45 cities of RF. Total direct medical costs (DCm) of treating T2DM and its complications and comorbidities amounted to 105337 rubles (\$2742) per patient per year; direct non-medical costs (DCn) amounted to 24518 rubles $(\$ 638)$ per patient per year; indirect costs (IC) amounted to 149754 rubles (\$3898) per patient per year. The total cost of T2DM in RF in 2014 year amounted to 279609 rubles ( $\$ 7278)$ per patient. The total cost of T2DM in RF in 2014 amounted to 279609 rubles per patient.

CONCLUSIONS: More than half $(53,5 \%)$ of the total cost of T2DM is the loss of GDP due to patients' disability. The DCm constitute $37,7 \%$ of the total cost of the disease, of which $57 \%$ is spent on treatment of T2DM complications and concomitant diseases, while only $10 \%$ is spent on glucose-lowering therapies.

KEYWORDS: type 2 diabetes mellitus; pharmacoepidemiology; analysis; cost of Illness; direct medical costs; direct non-medical costs; indirect costs

Сахарный диабет (СД) является серьезной медико-социальной проблемой, что обусловлено его большой распространенностью, особенно среди лиц трудоспособного возраста, хроническим течением, ранней инвалидизацией и высокой смертностью от сердечно-сосудистых осложнений. По данным Международной Федерации Диабета (IDF), в 2015 г. в мире было зарегистрировано 415 млн взрослых, страдающих СД, а еще у 318 млн человек выявлено нарушение толерантности к глюкозе, что значительно повышает риск развития СД в будущем [1]. Эксперты Всемирной организации здравоохранения (ВО3) утверждают, что «СД занимает третье место среди непосредственных причин смерти населения после сердечно-сосудистых и онкологических заболеваний и одновременно третье место среди ведущих факторов риска преждевременной смерти после высокого артериального давления и потребления табака» [2], поэтому решение вопросов, связанных с проблемой СД, поставлено во многих странах на государственный уровень.

По данным Государственного регистра больныхсахарным диабетом, на начало 2015 г. в Российской Федерации (РФ) число больных СД 2 типа (СД2) составляло не менее 2,8\% населения (4,094 млн человек) [3]. В то же время результаты первого национального эпидемиологического кросс-секционного исследования NATION, проведенного в 2013-2015 гг., продемонстрировали, что «реальная распространенность СД2 среди населения оказалась в 2 раза выше и составила 5,4\%, причем более чем у 50\% субъектов СД был ранее не диагностирован» [4]. Согласно прогнозу IDF, к 2040 г. в России ожидается увеличение числа больных СД в 2 раза - до 12,4 млн.

В связи с высокой смертностью, большим количеством осложнений и необходимостью постоянной пожизненной терапии и контроля, СД не только приносит страдания людям, но и является огромной социально-экономической проблемой. В настоящее время не менее $12 \%$ общемировых затрат на здравоохранение прихо- дятся на долю СД [1]. Все затраты, связанные с СД, подразделяют на прямые и непрямые. Прямые затраты включают расходы, связанные с диагностикой заболевания и его осложнений, контролем уровня сахара, лекарственной терапией, оказанием амбулаторной и стационарной помощи. Непрямые затраты включают расходы, связанные с преждевременной смертью, временной или постоянной утратой трудоспособности и инвалидностью. Как прямые, так и непрямые затраты являются тяжелым экономическим бременем как для самих пациентов, страдающих СД, и членов их семей, так и для системы здравоохранения и бюджета государства. Таким образом, СД является одним из серьезных препятствий на пути устойчивого экономического развития государства.

Согласно отчету IDF, в 2014 г. более чем у 80\% государств расходы, связанные с СД, составляют от 5\% до $20 \%$ общих затрат на здравоохранение, включая оказание профилактической и лечебной медицинской помощи, планирование семьи, питание, оказание неотложной медицинской помощи.

В связи с высокой распространенностью СД особую актуальность приобрели исследования, направленные на определение размеров экономического ущерба, наносимого СД2 [5, 6]. Оценка не только медицинской, но и социальной, и экономической составляющих современных подходов к лечению СД2 является одним из приоритетных направлений клинико-экономических исследований во всех странах мира. Подобная комплексная оценка имеет важное значение и для отечественного здравоохранения [7, 8].

Одним из наиболее важных инструментов, способствующих принятию решений в системе здравоохранения, является клинико-экономический анализ. Высокая социальная значимость СД2 определяется его эпидемиологией, системой диагностического мониторинга, стандартами медицинской помощи и реальной практикой лечения, а также социальным и экономическим бременем, выражающимся в стоимости болезни [10]. 
В ранее опубликованной первой части отчета о результатах наблюдательного эпидемиологического исследования (по типу поперечного среза) ФОРСАЙТ-СД2 был проведен анализ основных эпидемиологических и демографических показателей, параметров гликемического контроля среди больных СД2, проживающих в различных по численности населения городах и населенных пунктах РФ, в условиях типичной амбулаторно-поликлинической практики [9]. Установлено, что в 2014 г. примерно у 1/3 обследованных пациентов (36\%) отмечался неадекватный гликемический контроль $\left(\mathrm{HbA}_{1 c}>8 \%\right)$, у большинства больных (80\%) было выявлено наличие от двух до шести хронических осложнений СД, а также несоответствие частоты проведения профилактических мероприятий по предупреждению развития осложнений СД2 существующим стандартам оказания специализированной медицинской помощи.

Проблему обеспечения пациентов доступной и качественной медицинской помощью невозможно решить, не располагая достоверными данными об экономических затратах, которые несет государство при лечении больных СД2. Информация о «стоимости болезни» может способствовать более объективному распределению финансовых ресурсов, выбору наиболее обоснованной диагностической и лечебно-профилактической стратегии для принятия взвешенных решений в условиях объективной ограниченности ресурсов.

Настоящая публикация представляет вторую часть отчета по исследованию ФОРСАЙТ-СД2 и посвящена расчету стоимости лечения СД2 и его осложнений на основании результатов типичной практики лечения СД2 в различных по численности населения городах РФ.

\section{ЦЕЛЬ}

Цель исследования заключалась в расчете общих затрат, связанных с СД2, на одного пациента в РФ и анализе структуры основных расходов государства, связанных с данным заболеванием.

\section{МАТЕРИАЛЫ И МЕТОДЫ}

При проведении анализа СД2 в РФ авторы опирались на данные «Российского многоцентрового фармакоэпидемиологического исследования по изучению реальной практики оказания медицинской помощи при СД 2 типа (ФОРСАЙТ-СД2)». Информацию по каждому пациенту собирали из нескольких источников: 1) демографическую, клиническую информацию, сведения о результатах диагностических исследований и проводимой фармакотерапии получали из первичной медицинской документации (амбулаторной карты пациента, выписных эпикризов из истории болезни стационарного обследования); 2) социально-демографические данные, расширенные анамнестические сведения и дополнительную информацию о фармакотерапии собирали при анкетировании пациентов. Фармакоэпидемиологический анализ проводился в соответствии с международной методологией ATX/ DDD с расчетом средней назначенной суточной дозы (PDD) для каждого лекарственного средства (ЛС), учитываемого по международным непатентованным наименованиям (МНH) [12].
Для проведения анкетирования исследовательской группой под руководством главного эндокринолога М3 РФ академика РАН Ивана Ивановича Дедова был разработан Опросник пациента ФОРСАЙТ-СД2. Собранные данные врачами-исследователями переносились в индивидуальные регистрационные карты пациентов.

В исследование включали пациентов старше 18 лет, страдающих СД2 не менее одного года, получающих сахароснижающую терапию, которые обращались за медицинской помощью к врачам-эндокринологам амбулаторно-поликлинических медицинских учреждений РФ с 01.01.2014 по 31.12.2014. В окончательный анализ были включены 2014 больных СД2 из 45 различных городов и поселков городского типа РФ, согласившихся принять участие в исследовании и подписавших формы информированного согласия (Информационный листок пациента).

Анализ стоимости болезни (cost of illness, COI) является одним из методов клинико-экономического анализа (КЭА), который используется для оценки и планирования затрат, определения тарифов для взаиморасчетов между субъектами системы здравоохранения и медицинского страхования [11].

Расчет общих затрат на лечение СД2, его осложнений и сопутствующих заболеваний, а также отчетность по ним осуществлялись на один год. Анализ стоимости болезни проводился с позиции государства и включал расчет всех затрат, обусловленных СД2.

Общие затраты рассчитывались по формуле:

$C O I=D C(m)+D C(n)+I C$,

где COI - показатель стоимости болезни (общие затраты);

DC - прямые затраты (Direct Costs), включают прямые медицинские $(\mathrm{DCm})$ и прямые немедицинские (DCn) затраты;

IC - непрямые затраты (Indirect Costs).

В ходе проведенного исследования анализировались источники прямых медицинских заmpam (DCm) и прямых немедицинских затрат (DCn) в пересчете на 1 больного, а также непрямые затраты (IC). В качестве прямых медицинских затрат принимали государственные расходы на лечение СД2, его осложнений и наиболее значимых сопутствующих заболеваний, непрямых затрат - государственные расходы на выплату пособий по инвалидности.

Отдельно были проанализированы личные расходы больных на покупку ЛС и изделий медицинского назначения (ИМН) в амбулаторных условиях (тест-полоски к глюкометру).

Прямые медицинские затраты (DCm) на обследование и лечение одного пациента с СД2 рассчитывали по формуле:

$\mathrm{DCm}=\mathrm{C} 1+\mathrm{C} 2+\mathrm{C} 3+\ldots+\mathrm{Cn}$,

где $\mathbf{D C m}$ - прямые затраты на обследование и лечение;

C1, C2, C3, Cn - стоимость основных статей расходов на обследование и лечение одного пациента с СД2.

Были выделены следующие прямые затраты, обусловленные СД2:

- сахароснижающие препараты, включая инсулин (C1); - гипотензивная и гиполипидемическая терапия (C2);

- амбулаторно-поликлиническая помощь больным с СД2 (С3); 
Таблица 1. Стоимость госпитализации в связи с СД2 или его осложнениями

\begin{tabular}{|c|c|c|c|}
\hline Причина госпитализации & $\begin{array}{c}\text { Номер клини- } \\
\text { ко-статистиче- } \\
\text { ской группы }\end{array}$ & $\begin{array}{c}\text { Коэффици- } \\
\text { ент затрато- } \\
\text { емкости }\end{array}$ & $\begin{array}{l}\text { Итоговая } \\
\text { стоимость } \\
\text { госпитали- } \\
\text { зации, руб. }\end{array}$ \\
\hline Сахарный диабет без осложнений и сопутствующих заболеваний (C4) & 35 & 1,02 & 19569,92 \\
\hline Диабетическая ретинопатия & 21 & 0,682 & 13084,99 \\
\hline Диабетическая нейропатия & 52 & 1,25 & 23982,75 \\
\hline Заболевания периферических сосудов & 106 & 1,21 & 23215,30 \\
\hline Диализ & 72 & 2,31 & 44320,12 \\
\hline Синдром диабетической стопы & 162 & 1,52 & 29163,02 \\
\hline Острый или повторный инфаркт миокарда & 40 & 1,94 & 37221,23 \\
\hline Сердечная недостаточность & 41 & 1,1 & 21104,82 \\
\hline Инсульт головного мозга & 54 & 1,89 & 36261,92 \\
\hline Диабетическая остеоартропатия & 173 & 1,67 & 32040,95 \\
\hline Диабетическая нефропатия & 112 & 1,66 & 31849,09 \\
\hline Хроническая почечная недостаточность & 112 & 1,66 & 31849,09 \\
\hline Артериальная гипертензия & 27 & 0,7 & 13430,34 \\
\hline Нарушения ритма сердца & 69 & 1,12 & 21488,54 \\
\hline Стенокардия & 194 & 0,78 & 14965,24 \\
\hline Острое нарушение мозгового кровообращения & 89 & 2,54 & 48349,22 \\
\hline Неалкогольная жировая болезнь печени & 19 & 0,86 & 16500,13 \\
\hline Мочекаменная болезнь & 27 & 0,49 & 9401,24 \\
\hline Подагра & 173 & 1,67 & 32040,95 \\
\hline
\end{tabular}

- стационарное лечение больных, обусловленное наличием СД2 (C4);

- амбулаторное и стационарное лечение хронических осложнений СД2 и сопутствующих заболеваний (C5).

Затраты на лекарственную терапию $(\mathrm{C1}, \mathrm{C2})$. В анализ были включены пероральные сахароснижающие препараты (ПССП), неинсулиновые сахароснижающие препараты (лираглутид), инсулины, а также гипотензивные и гиполипидемические ЛС. Рассчитаны усредненные показатели стоимости годового курса лечения пациентов с СД2.

Для определения затрат на каждое применяемое ЛС была взята максимальная расчетная цена за упаковку в розничной аптечной сети в Государственном реестре отпускных цен из «Перечня жизненно необходимых и важнейших ЛС (ЖНВЛП)» от 26.12.2014 г. с учетом налога на добавочную стоимость [13]. Если ЛС отсутствовало в Государственном реестре отпускных цен, то брались средние арифметические розничные цены по базе данных 40 аптек г. Москвы, выбранных случайным образом на информационном интернет-портале «Медицина для вас» (www.medlux.ru) на 25.12.2014 [14].

Для проведения анализа было допущено, что ЛС применяли в одной и той же дозе в течение года. Учитывая разницу в стоимости ЛС разных производителей, использовали средневзвешенную стоимость лекарственной терапии СД2. Средняя стоимость 1 мг ПССП равнялась стоимости 1 упаковки, деленной на количество таблеток в упаковке, а затем на количество ЛС, содержащегося в 1 таблетке, выраженное в миллиграммах. Ана- логичным образом была рассчитана средняя стоимость 1 мг гипотензивных и гиполипидемических ЛС. Средняя стоимость годового курса лечения 1 пациента при назначении ПССП (руб. год) равнялась произведению рассчитанной средневзвешенной стоимости 1 мг ЛС и средней назначенной суточной дозы (PDD), выраженной в мг/сут, умноженной на 365 дней. Среднюю стоимость годового курса лечения инсулином рассчитывали, исходя из стоимости 1 ЕД инсулина, которая равнялась отношению стоимости 1 упаковки инсулина и количества единиц инсулина в 1 упаковке для шприц-ручек или в одном флаконе. Средняя стоимость годового курса лечения инсулином на 1 пациента (руб./год) равнялась произведению рассчитанной средневзвешенной стоимости 1 ЕД инсулина и PDD (ЕД/сут), умноженной на 365 дней.

В итоге были рассчитаны средняя годовая стоимость лекарственной терапии 1 больного СД2 и общая стоимость терапии сопутствующих заболеваний и хронических осложнений СД2 исследуемой когорты пациентов.

Затраты, связанные с оказанием амбулаторной медицинской помощи (С3), были рассчитаны в соответствии с Постановлением Правительства Российской Федерации от 18 октября 2013 г. № 932 «О программе государственных гарантий бесплатного оказания гражданам медицинской помощи на 2014 год» [15]. Средние нормативы финансовых затрат на амбулаторное посещение одного специалиста, установленные на 2014 г., за счет средств обязательного медицинского страхования составляли $\mathbf{3 1 8 , 4}$ руб. Суммарные затраты на оказание амбулаторной помощи рассчитаны как произведе- 
Таблица 2. Характеристика включенных в исследование пациентов

\begin{tabular}{|c|c|c|}
\hline Характеристика & & Значение \\
\hline Медиана возраста, лет (95\% ДИ) & & $60(54 ; 75)$ \\
\hline Медиана длительности СД2, лет (95\% ДИ) & & $7(3 ; 12)$ \\
\hline Мужчины, N (\%) & & $640(31,8)$ \\
\hline Женщины, N (\%) & & $1368(67,9)$ \\
\hline Пенсионеры, N (\%) & & $838(41,6)$ \\
\hline Работают, N (\%) & & $796(39,5)$ \\
\hline Не работают, N (\%) & & $403(20,0)$ \\
\hline Пропускали работу по болезни, N (\%) & & $584(29,0)$ \\
\hline \multirow[t]{4}{*}{ Инвалидность, N (\%) } & & $765(38,0)$ \\
\hline & І группа, N (\%) & $43(2,5)$ \\
\hline & II группа, N (\%) & $28616,5)$ \\
\hline & III группа, N (\%) & $329(19,0)$ \\
\hline Неработающие инвалиды, N (\%) & & $564(28,2)$ \\
\hline \multicolumn{3}{|c|}{ Среднее количество дней нетрудоспособности среди работающих инвалидов } \\
\hline & І группа, N (\%) & $5(16)$ \\
\hline & II группа, N (\%) & $30(29)$ \\
\hline & III группа, N (\%) & $56(24)$ \\
\hline
\end{tabular}

ние установленного норматива финансирования данной медицинской услуги и числа эпизодов оказания данного вида помощи в год.

Для расчета затрат на оказание стационарной помощи больным СД2 без осложнений и сопутствующих заболеваний (C4) и с наличием осложнений СД и сопутствующих заболеваний (C5) были использованы коэффициенты затратоемкости, предусмотренные системой оплаты по клинико-статистическим группам (КСГ) [16], и базовой стоимости госпитализации больного с СД2, равной в 2014 г. 19 186,2 руб. (табл. 1).

Для расчета итоговой стоимости госпитализации была использована следующая формула:

COICT $=$ Cost $_{\text {Сд2 }} \times K_{3}$,

где $\mathbf{C O I c m}$ - затраты на оказание стационарной помощи больным с СД2; с СД2;

Cost $_{\text {сд2 }}$ - базовая стоимость госпитализации больного

Кз - коэффициент затратоемкости в зависимости от КСГ.

Расчет частных (личных) затрат пациентов на покупку ЛС и ИМН (C6) оценивали по результатам опроса пациентов об их средних ежемесячных дополнительных личных расходах.

Анализ прямых немедицинских затрат (DCn) (расходы государства на выплаты пособий по инвалидности) рассчитывали на основании количества больных, вошедших в исследование, имеющих группу инвалидности (табл. 2), и размера ежемесячной пенсии по инвалидности, которая в 2014 г. составляла для инвалидов I группы - 8647,51 руб./мес, ІІ группы - 4323,74 руб./мес, ІІІ группы - 3675,20 руб./мес; ежемесячной единовременной денежной выплаты, которая составляла для I группы 2974,03 руб./мес, II группы - 2123,92 руб./мес, III группы 1700,23 руб./мес; и ежемесячного социального пакета (ЛС, санатории, проезды) - 881,63 руб./мес $[17,18]$.
Анализ непрямых (косвенных) затрат (IC) осуществлялся на один год.

Непрямые затраты рассчитывали с помощью формулы: $I C=I C 1+I C 2+I C 3+I C 4$,

где IC - непрямые затраты;

IC1, IC2, IC3, IC4 - стоимость основных статей расходов одного пациента с СД2.

Были выделены следующие непрямые затраты, обусловленные СД2:

- расчет недополученного ВВП (ВВП на душу населения) вследствие потери заработка из-за временной нетрудоспособности граждан в трудоспособном возрасте (IC1);

- выплаты заработной платы по временной нетрудоспособности (IC2);

- расчет недополученного ВВП вследствие потери заработка из-за временной нетрудоспособности среди работающих инвалидов (IC3);

- потери ВВП, связанные с инвалидностью (IC4).

Недополученный ВВП вследствие потерь заработка из-за временной нетрудоспособности граждан в трудоспособном возрасте (IC1), которые несут государство и общество в целом, как упущенную выгоду в производстве внутреннего валового продукта (ВВП) рассчитывали, исходя из количества работающих лиц трудоспособного возраста, умноженного на среднее количество дней нетрудоспособности за прошедший год и на средний ВВП в сутки, равный 1342,81 руб./сут (объем ВВП на душу населения в 2014 г. составлял 488782 руб. [19]).

При расчете выплаты заработной платы по нетрудоспособности (IC2) величину средней начисленной заработной платы по стране за 2014 г. умножали на расчетное количество дней временной нетрудоспособности в связи с СД2. Средняя заработная плата в 2014 г. в РФ составляла 32495 руб./мес, или 1 071,26 руб./сут [19]. 
Таблица 3. Структура потребления и стоимость терапии неинсулиновыми сахароснижающими ЛС у пациентов с СД2 в РФ, 2014 г. (N=1800)

\begin{tabular}{|c|c|c|c|c|c|c|c|}
\hline \multirow[b]{2}{*}{ МНH (код АТХ) } & \multicolumn{3}{|c|}{ Структура назначений } & \multirow{2}{*}{$\begin{array}{c}\text { Средняя } \\
\text { стоимость ЛС в год } \\
\text { на } 1 \text { пациента, руб. }\end{array}$} & \multicolumn{3}{|c|}{$\begin{array}{l}\text { Структура расходов } \\
\text { на ПССП в год }\end{array}$} \\
\hline & $\mathrm{N}$ & $\%$ & $\begin{array}{l}\text { \% внутри } \\
\text { группы }\end{array}$ & & $\mathrm{N}$ & $\%$ & $\begin{array}{c}\text { \% внутри } \\
\text { группы }\end{array}$ \\
\hline Метформин (А10ВА02) & 1066 & 59,2 & & 4396 & 4685879 & 36,9 & \\
\hline $\begin{array}{l}\text { Метформин + производные сульфо- } \\
\text { нилмочевины (A10BD02) }\end{array}$ & 71 & 3,9 & & 5689 & 403919 & 3,2 & \\
\hline $\begin{array}{l}\text { Метформин + ингибиторы ДПП-4 } \\
\text { (A10BD07/ A10BD07) }\end{array}$ & 54 & 3,0 & & 30662 & 1655748 & 13,0 & \\
\hline $\begin{array}{l}\text { Производные сульфонилмочевины } \\
\text { (А10ВB) }\end{array}$ & 506 & 28,1 & & 5126 & 2593738 & 20,4 & \\
\hline - Глимепирид (A10BВ12) & 155 & & 30,6 & 6598 & 1324898 & & 51,1 \\
\hline - Гликлазид (А10ВВ09) & 267 & & 52,8 & 4334 & 1157078 & & 44,6 \\
\hline - Глибенкламид (А10ВВ01) & 82 & & 16,2 & 1256 & 103032 & & 4,0 \\
\hline - Гликвидон (А10ВВ08) & 2 & & 0,4 & 4380 & 8760 & & 0,3 \\
\hline Ингибиторы ДПП-4 (А10ВН) & 93 & 5,2 & & 23727 & 2206617 & 17,4 & \\
\hline - Ситаглиптин 100 мг №28 (А10ВН01) & 6 & & 6,5 & 38873 & 233238 & & 10,6 \\
\hline - Вилдаглиптин 50 мг №28 (А10ВН02) & 72 & & 77,4 & 23433 & 1687176 & & 76,5 \\
\hline - Саксаглиптин 5 мг №30 (А10ВН03) & 11 & & 11,8 & 19309 & 212399 & & 9,6 \\
\hline - Линаглиптин 5 мг №30 (А10ВН05) & 4 & & 4,3 & 18451 & 73804 & & 3,3 \\
\hline Агонисты ГПП-1 & 9 & 0,5 & & 129056 & 1161504 & 9,1 & \\
\hline $\begin{array}{l}\text { - Лираглутид } 6 \text { мг/мл } 3 \text { мл №2 } \\
\text { (А10ВХ07) }\end{array}$ & 7 & & 77,8 & 149504 & 1046528 & & 90,1 \\
\hline - Эксенатид 250 мкг/мл (А10ВХ04) & 2 & & 22,2 & 57488 & 114976 & & 9,9 \\
\hline \multicolumn{8}{|l|}{ Тиазолидиндионы } \\
\hline - Пиоглитазон 30 мг №30 (A10BG03) & 1 & 0,1 & 100,0 & 6077 & 6077 & $<1$ & 100 \\
\hline Итого & 1800 & 100 & & & 11444612 & 100 & \\
\hline
\end{tabular}

Расчет недополученного ВВП вследствие пропуска работы из-за временной нетрудоспособности среди работающих инвалидов (IC3). Для этого количество работающих инвалидов I, II и III группы умножали на среднее количество дней нетрудоспособности за прошедший год соответственно.

Потери ВВП, связанные с инвалидностью (IC4), определяли следующим образом: число неработающих инвалидов (табл. 1) было умножено на ВВП на душу населения, в результате чего была получена цифра непрямых затрат общества с учетом инвалидности.

\section{Статистический анализ}

Социально-демографические характеристики пациентов анализировались методами описательной статистики с помощью пакета прикладных программ Portable PASW Statistics 18. Непрерывные данные в случае нормального распределения представлены в виде: среднее значение (стандартное отклонение), для распределений отличных от нормального - в виде: медиана (интерквартильная широта - 25-й и 75-й процентиль).

\section{РЕЗУЛЬТАТЫ}

Из 2014 пациентов, включенных в исследование ФОРСАЙТ-СД2, мужчины составили 31,8\%, женщины - 67,9\%.
Возраст больных варьировался в пределах от 18 до 90 лет, средний возраст составил 60 лет (при 95\% доверительном интервале (ДИ) от 54 до 75 лет). Средняя длительность заболевания составила 7,0 лет (3-12 лет, 95\% ДИ) (см. табл. 2).

Среди хронических осложнений СД2 отмечали высокую распространенность диабетической ретинопатии $(63,2 \%)$ и периферической нейропатии (63,3\%), синдрома диабетической стопы (13,8\%), диабетической остеоартропатии (6,8\%). Диабетическую нефропатию наблюдали у 34,4\% больных, из них у 7,8\% - стадию хронической почечной недостаточности. В исследуемой когорте больных фиксировали высокую частоту сердечно-сосудистых заболеваний. Первое место по частоте встречаемости занимала артериальная гипертензия (АГ), которую выявили у $69,1 \%$ пациентов, далее следовали нарушения сердечного ритма - 29,4\%, стенокардия - 27,3\%, сердечная недостаточность - 16,3\%, инфаркт миокарда в анамнезе (ИБС) - 10,2\%, острое нарушение мозгового кровообращения (ОНМК) - 7\% пациентов. Помимо АГ, которая являлась наиболее частым сопутствующим заболеванием, в исследуемой группе больных отмечали высокую распространенность неалкогольной жировой болезни печени (18,9\%), мочекаменной болезни (13,3\%), подагры (5\%). Схематичный анализ частоты осложнений СД2 представлен на рис. 1, а подробный - среди пациентов, 
Таблица 4. Структура потребления и стоимость инсулинов у пациентов с СД2 в РФ, 2014 г., N=538

\begin{tabular}{|c|c|c|c|c|c|c|c|}
\hline \multirow{2}{*}{ Препараты инсулина } & \multicolumn{3}{|c|}{ Структура назначений } & \multirow{2}{*}{$\begin{array}{l}\text { Средняя стоимость в год } \\
\text { на } 1 \text { пациента, руб }\end{array}$} & \multicolumn{3}{|c|}{$\begin{array}{c}\text { Структура расходов на ин- } \\
\text { сулины в год }\end{array}$} \\
\hline & $\mathrm{N}$ & $\%$ & $\begin{array}{l}\text { \% внутри } \\
\text { группы }\end{array}$ & & $\mathrm{N}$ & $\%$ & $\begin{array}{l}\text { \% внутри } \\
\text { группы }\end{array}$ \\
\hline $\begin{array}{l}\text { Инсулин и его аналоги короткого } \\
\text { действия }\end{array}$ & 328 & 37,9 & & 3816 & 1141179 & 20,3 & \\
\hline $\begin{array}{l}\text { - Аналоги инсулина человека } \\
\text { короткого действия }\end{array}$ & 94 & & 28,7 & 4971 & 467266 & & 40,9 \\
\hline - Инсулины короткого действия & 234 & & 71,3 & 2660 & 673913 & & 59,1 \\
\hline $\begin{array}{l}\text { Инсулины средней продолжитель- } \\
\text { ности и аналоги инсулина длитель- } \\
\text { ного действия }\end{array}$ & 463 & 53,5 & & 7040 & 3950085 & 70,2 & \\
\hline $\begin{array}{l}\text { - Инсулины средней продолжи- } \\
\text { тельности действия и их ана- } \\
\text { логи }\end{array}$ & 244 & & 52,7 & 3641 & 1025010 & & 25,9 \\
\hline $\begin{array}{l}\text { - Инсулины длительного дей- } \\
\text { ствия и их аналоги }\end{array}$ & 219 & & 47,3 & 10439 & 2925075 & & 74,1 \\
\hline $\begin{array}{l}\text { Микс-инсулины (инсулины сред- } \\
\text { ней продолжительности действия } \\
\text { и их аналоги в комбинации с инсу- } \\
\text { линами короткого действия) }\end{array}$ & 75 & 8,7 & & 7168 & 537561 & 9,6 & \\
\hline Средневзвешенная стоимость базис & болюс & ой инс & улинотераг & пии & & 705 p) & \\
\hline Средневзвешенная стоимость базис & ной ин & /линол & ерапии & & & 40 py & \\
\hline Средневзвешенная стоимость инсул & иноте & пии $\mathrm{N}$ & кс-инсул & нами & & 31 py & \\
\hline
\end{tabular}

проживающих в различных по численности населения городах РФ, опубликован в первой части отчета по исследованию ФОРСАЙТ-СД2 [9].

\section{Анализ прямых медицинских затрат на лечение СД2}

\section{1. Затраты на сахароснижающие ЛС (С1).}

Результаты фармакоэпидемиологического анализа представлены в виде терапевтического профиля потребления ПССП, неинсулиновых сахароснижающих препаратов и инсулинов в натуральном и денежном выражении. По данным, полученным в исследовании ФОРСАЙТ-СД2, в различных городах РФ пациенты с СД2 получали лечение ПССП, которое включало шесть подгрупп, согласно ATX-классификации, в виде монотерапии или в виде различных комбинаций: на первом месте по частоте назначений был метформин - 59,2\%, на втором - производные сульфонилмочевины (ПСМ) - 28,0\%, на третьем - ингибиторы ДПП-4 - 5,2\%. Оставшиеся 3 подгруппы ПССП назначались редко: фиксированные комбинации ПСМ + метформин $-3,5 \%$, метформин + ингибиторы дПП-4 - 2,7\%, агонисты или аналоги ГПП-1 получали 0,5\% больных (табл. 3, Приложение 1). Лечение тиазолидиндионами (пиоглитазоном) получал 1 пациент.

Наиболее затратной была терапия инновационными ЛС - агонистами ГПП-1, средневзвешенная стоимость которой составила 129056 руб./год на 1 пациента. На втором месте по стоимости при проведении монотерапии была терапия фиксированной комбинацией - метформин + ингибиторы ДПП-4 - 30662 руб./год и терапия ингибиторами ДПП-4 - 23727 руб./год на 1 пациента.
Наименее затратной была терапия метформином - 4396 руб./год и ПСМ - 5126 руб./год. Более выгодной терапевтической стратегией было лечение фиксированной комбинацией - метформин + ПСМ 5689 руб./год, однако данный вид терапии получали лишь 3,5\% больных.

В обследуемой группе пациентов с СД2 лечение инсулином получали 26,7\% больных. На базис-болюсном режиме инсулинотерапии находились 16,3\% больных исследуемой когорты, на комбинированной терапии базальный инсулин + ПССП - 6,7\%; терапию микс-инсулинами получали $3,7 \%$ пациентов с СД2. Структура потребления и стоимость различных схем инсулинотерапии представлены в табл. 4, Приложении 2.

Наиболее затратной схемой лечения была терапия аналогами инсулина человека ультракороткого и длительного действия при базис-болюсном режиме введения инсулина, составившая 18328 руб./год на 1 пациента, тогда как применение инсулинов человека короткого действия с инсулином человека средней продолжительности действия составило 7081 руб./год на 1 пациента.

Средневзвешенная стоимость базис-болюсной инсулинотерапии составила 12705 руб. на 1 больного в год. В то же время средневзвешенная стоимость лечения при применении микс-инсулинов составила 6131 руб. на 1 больного в год, базисной инсулинотерапии - 7040 руб. на 1 больного в год.

Анализ структуры затрат на сахароснижающую терапию показал, что $38 \%$ затрат приходилось на инсулинотерапию, 35\% - на метформин и ПСМ, 11\% - на ингибиторы ДПП-4, 10\% - на метформин + ингибиторы ДПП-4 и ПСМ + метформин (табл. 5). 
Таблица 5. Структура потребления сахароснижающей терапии (в \%) и средняя стоимость фармакотерапии 1 пациента с СД2 в год

Вид терапии

Доля назначений в количественном выражении, $\mathrm{n}^{*}(\%), \mathrm{N}=2014^{* *}$
Средняя стоимость лечения в зависимости от вида ССП на 1 пациента в год, руб.

\section{Метформин}

Производные сульфонилмочевины

$\begin{array}{cc}1066(59,2) & 4396 \\ 506(28) & 5126 \\ 1(0,0) & 6077 \\ 93(5,2) & 23727 \\ 71(3,5) & 5689 \\ 54(2,7) & 30662 \\ 9(0,5) & 29056 \\ 328(16,2) & 12705 \\ 75(3,7) & 6131 \\ 463(23) & 7040\end{array}$

\section{Итого в год на всех \\ больных на данной терапии, руб. (\%)}

$4685879(22,75)$

$2593738(12,59)$

$6077(0,03)$

$2206617(10,71)$

$403919(1,96)$

$1655748(8,04)$

$1161504(5,64)$

$4167240(20,23)$

$459825(2,23)$

$3259520(15,82)$

10228 руб.

Средневзвешенная стоимость сахароснижающей терапии на 1 пациента в год

Таким образом, средневзвешенные затраты на лечение 1 больного СД2 сахароснижающими препаратами и инсулинами в 2014 г. составили 10228 руб. в год, или 852 руб. в месяц.

\section{2. Затраты на лекарственную терапию артериаль-} ной гипертензии и дислипидемии (С2).

Среди всех сопутствующих заболеваний наиболее часто у больных СД2 наблюдалась артериальная гипер- тензия (69,1\%), по поводу которой постоянную терапию получали 97,6\% (рис. 1). Наиболее часто назначаемыми гипотензивными препаратами были ЛС из группы ингибиторы АПФ - 33,9\%, диуретики получали 20,3\% больных, $\beta 1$-адреноблокаторы - 19,6\%, антагонисты рецепторов ангиотензина II - 12,6\%, блокаторы кальциевых каналов - 12,3\% и агонисты имидазолиновых рецепторов - 1,4\% (табл. 6, Приложение 3).

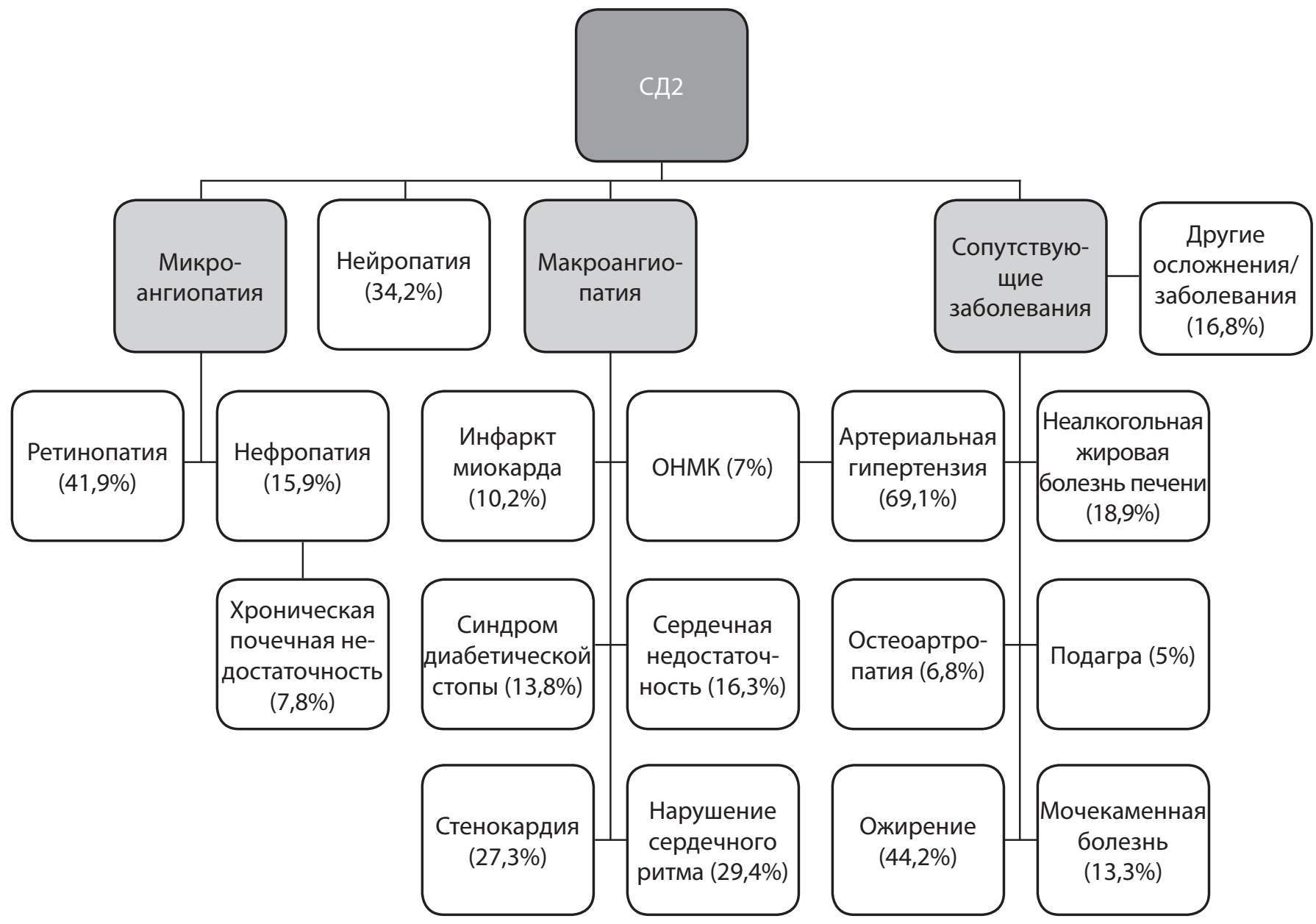

Рис. 1. Распространенность осложнений и сопутствующих заболеваний среди пациентов с сахарным диабетом 2 типа в исследовании ФОРСАЙТ-СД2 [9]. 
Таблица 6. Структура потребления и стоимость гипотензивной и гиполипидемической терапии у пациентов с СД2 в РФ, 2014 г.

\begin{tabular}{|c|c|c|c|c|c|c|c|}
\hline \multirow[b]{2}{*}{ Группа, МНH } & \multicolumn{3}{|c|}{ Структура назначений } & \multicolumn{4}{|c|}{$\begin{array}{c}\text { Структура расходов } \\
\text { на терапию в год }\end{array}$} \\
\hline & $\mathrm{N}$ & $\%$ & $\begin{array}{c}\text { \% внутри } \\
\text { группы }\end{array}$ & $\begin{array}{l}\text { Средняя стоимость ЛС } \\
\text { в год на } 1 \text { пациента, руб. }\end{array}$ & $\begin{array}{c}\text { Стои- } \\
\text { мость, } \\
\text { руб. }\end{array}$ & $\%$ & $\begin{array}{c}\text { \% внутри } \\
\text { группы }\end{array}$ \\
\hline
\end{tabular}

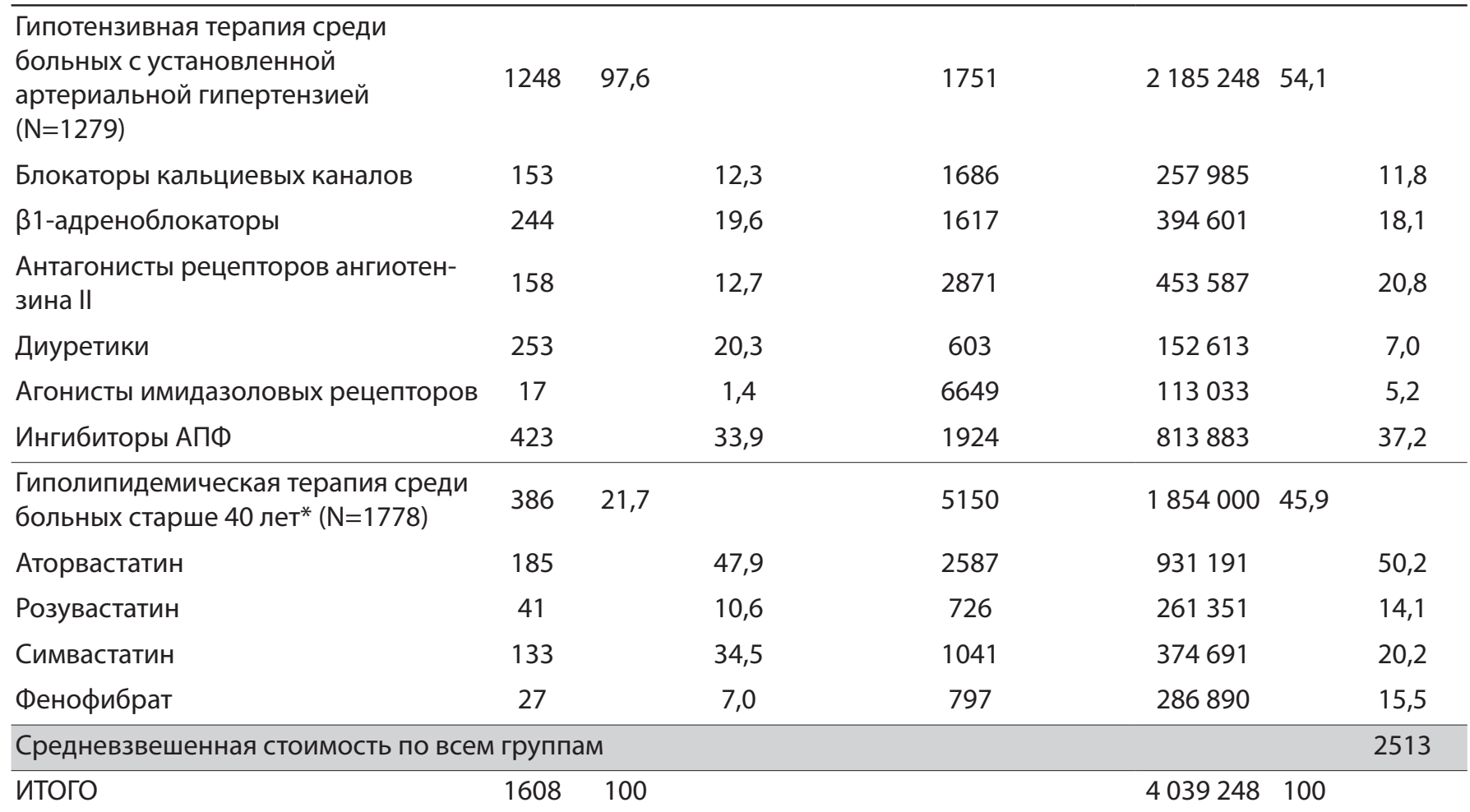

Примечание: * - В соответствии с Российскими и Европейскими рекомендациями по профилактике сердечно-сосудистых заболеваний гиполипидемическую терапию статинами должны получать все больные СД2 старше 40 лет [20, 21].

Наиболее затратной группой среди применявшихся гипотензивных ЛС были агонисты имидазолиновых рецепторов (моксонидин), составившей в денежном выражении 6649 руб. в год на 1 больного, наиболее дешевой - диуретики - 603 руб. в год на 1 больного. Средняя стоимость лечения ингибиторами АПФ составила 1924 руб. в год на 1 больного, антагонистами рецепторов ангиотензина II - 2871 руб. в год. Средневзвешенная стоимость гипотензивной терапии 1 человека в год составила 1751 руб.

В соответствии с отечественными и международными рекомендациями для профилактики развития сердечно-сосудистых заболеваний всем больным с диагнозом СД2 старше 40 лет показан постоянный пожизненный прием гиполипидемических ЛС с целью достижения целевых показателей уровня липопротеинов низкой плотности (ЛПНП) менее 2,5 ммоль/л при отсутствии сердечно-сосудистых заболеваний и менее 1,8 ммоль/л при их наличии, согласно отечественным и международным рекомендациям [20, 21]. В исследуемой когорте пациентов гиполипидемическую терапию в 2014 г. получали лишь 17,8\% больных. PPD ингибиторов ГМГ-КоА-редуктазы у большинства пациентов была ниже средней дозы, рекомендованной экспертами BО3. Так, PPD симвастатина составила 16 мг/день (всего получали 6,6\% больных), аторвастатина - 15 мг в день (9,2\%), розувастатина - 13 мг в день (2\%).

Следует отметить, что все ЛС, относящиеся к группе ингибиторов ГМГ-КоА-редуктазы, были представлены
Таблица 7. Основные характеристики оказания амбулаторной медицинской помощи больным СД2 в ЛПУ

\begin{tabular}{cc}
\hline Основные характеристики & Доля, \% \\
\hline Профиль ЛПУ для постоянного наблюдения пациентов
\end{tabular}

$$
\text { сСД2 }
$$

Поликлиника

Эндокринологический диспансер

Частный медицинский центр

Семейный врач

Другое

Специальность врача, постоянно наблюдающего пациентов С СД2

Эндокринолог 91,1

Терапевт

Кардиолог

Другой специалист

0,2

Частота посещения пациентами с СД2 врачей

Крайне редко

1 раз в год

2 раза в год

1 раз в 3 месяца

Ежемесячно

45,2 
Таблица 8. Затраты на амбулаторно-поликлиническую помощь

\begin{tabular}{|c|c|c|c|c|}
\hline Амбулаторные визиты к эндокринологу & $\begin{array}{c}\text { Доля } \\
\text { больных, \% }\end{array}$ & $\begin{array}{l}\text { Количество } \\
\text { больных, чел. }\end{array}$ & $\begin{array}{c}\text { Количество } \\
\text { посещений } \\
\text { в год, раз }\end{array}$ & $\begin{array}{c}\text { Стоимость амбула- } \\
\text { торных посещений, } \\
\text { руб. }\end{array}$ \\
\hline $\begin{array}{l}\text { Постоянно наблюдаются в поликлинике } \\
\text { или диспансере }\end{array}$ & 96,4 & 1942 & 13136 & 4182563 \\
\hline Ежемесячно & 45,2 & 878 & 10531 & 3352974 \\
\hline 4 раза в год & 25,3 & 491 & 1965 & 625592 \\
\hline 2 раза в год & 10,4 & 202 & 404 & 128580 \\
\hline 1 раз в год & 12,2 & 237 & 237 & 75417 \\
\hline В среднем на 1 больного в год, руб. (n=2014) & & & & 2077 \\
\hline
\end{tabular}

Таблица 9. Прямые медицинские затраты на лечение осложнений Сд2 и сопутствующих заболеваний

\begin{tabular}{|c|c|c|c|c|}
\hline \multirow{2}{*}{ Нозологическая форма } & \multirow{2}{*}{ Стоимость, руб. } & \multirow{2}{*}{ Кол-во больных, чел. } & \multicolumn{2}{|c|}{ Все пациенты } \\
\hline & & & Стоимость, руб. & $\%$ \\
\hline Артериальная гипертензия & 13430,34 & 1279 & $17177405^{*}$ & 14,2 \\
\hline Диабетическая ретинопатия & 13084,99 & 775 & 10140867 & 8,4 \\
\hline Диабетическая нейропатия & 29163,02 & 634 & 18489355 & 15,2 \\
\hline Нарушения сердечного ритма & 21488,54 & 545 & 11711254 & 9,7 \\
\hline Стенокардия & 14965,24 & 506 & 7572411 & 6,2 \\
\hline Неалкогольная жировая болезнь печени & 16500,13 & 350 & 5775046 & 4,8 \\
\hline Сердечная недостаточность & 21104,82 & 302 & 6373656 & 5,3 \\
\hline Нефропатия & 31849,09 & 294 & 9363632 & 7,7 \\
\hline Синдром диабетической стопы & 29163,02 & 255 & 7436570 & 6,1 \\
\hline Мочекаменная болезнь & 9401,24 & 247 & 2322106 & 1,9 \\
\hline Инфаркт миокарда & 37221,23 & 188 & 6997591 & 5,8 \\
\hline Хроническая почечная недостаточность & 31849,09 & 144 & 4586269 & 3,8 \\
\hline OHMK & 48349,22 & 130 & 6285399 & 5,2 \\
\hline Остеоартропатия & 32040,95 & 126 & 4037160 & 3,3 \\
\hline Подагра & 32040,95 & 93 & 2979808 & 2,5 \\
\hline \multicolumn{3}{|c|}{ Лечение осложнений СД2 и сопутствующих заболеваний на 1 больного в год (n=2014 чел.) } & 60203 & 100 \\
\hline
\end{tabular}

Примечание: * Стоимость гипотензивных ЛС, назначенных при амбулаторном ведении пациентов, в расчете не учитывалась.

Таблица 10. Общие прямые медицинские затраты на лечение СД2 в год

\begin{tabular}{lcc}
\hline \multicolumn{1}{c}{ Виды затрат } & Затраты, руб. & Доля затрат, \% \\
\hline Сахароснижающая терапия (С1) & 10228 & 10 \\
Гипотензивная и гиполипидемическая терапия (С2) & 2512 & 2 \\
Амбулаторно-поликлиническая помощь (С3) & 2077 & 2 \\
Стационарное лечение СД2 без учета осложнений (С4) & 10057 & 10 \\
Стационарное лечение СД2 сучетом осложнений и сопутствующих заболеваний (С5) & 60203 & 57 \\
Личные затраты пациентов (С6) & 20261 & 19 \\
Общие прямые медицинские затраты на лечение 1 пациента СД2 в год, руб. & 105337 & 100 \\
\hline
\end{tabular}

отечественными генерическими средствами, стоимость которых варьировала от 2168 руб./год для симвастатина в дозе 10 мг/день до 12264 руб./год для аторвастатина в дозе 80 мг/день. Фибраты получали 1,3\% больных.

Средневзвешенная стоимость терапии гиполипидемическими препаратами составила 5150 руб. в год на 1 больного.
Таким образом, при подсчете затрат на лекарственную терапию АГ и дислипидемии у пациентов с СД2 в исследовании ФОРСАЙТ-СД2 было выявлено, что общие затраты на 1 больного на антигипертензивные и гиполипидемические ЛС составили 2513 руб. в год (табл. 6, Приложение 3). 
Таблица 11. Прямые немедицинские затраты

\begin{tabular}{|c|c|c|c|c|}
\hline $\begin{array}{l}\text { Группа инва- } \\
\text { лидности }\end{array}$ & $\begin{array}{c}\text { Количество } \\
\text { человек }\end{array}$ & $\begin{array}{c}\text { Размер ежемесячной } \\
\text { пенсии по инвалидности, } \\
\text { руб./мес [17] }\end{array}$ & $\begin{array}{c}\text { Ежемесячный размер едино- } \\
\text { временной денежной выплаты, } \\
\text { руб./мес [17] }\end{array}$ & $\begin{array}{c}\text { Социальный пакет } \\
\text { руб./мес [17] }\end{array}$ \\
\hline I группа & 43 & 8647,51 & 2974,03 & 881,63 \\
\hline II группа & 286 & 4323,74 & 2123,92 & \\
\hline III группа & 329 & 3675,20 & 1700,23 & \\
\hline \multicolumn{4}{|c|}{ Прямые немедицинские затраты на 1 пациента в год } & 24518 \\
\hline
\end{tabular}

Таблица 12. Недополученный ВВП вследствие пропуска работы по нетрудоспособности у работающих инвалидов

\begin{tabular}{lccc}
\hline \multicolumn{1}{c}{ Группа } & Количество работающих \\
инвалидности & инвалидов, чел. & $\begin{array}{c}\text { Ср. кол-во дней } \\
\text { нетрудоспособности }\end{array}$ & $\begin{array}{c}\text { Недополученный ВВП, } \\
\text { руб. }\end{array}$ \\
\hline І группа & 5 & 16 & 107424,00 \\
II группа & 30 & 29 & 1168236,00 \\
III группа & 56 & 24 & 1804723,20 \\
На 1 пациента, руб. в год & & & 1529,49 \\
\hline
\end{tabular}

3. затраты на оказание амбулаторно-поликлинической помощи (СЗ) больным с СД2.

В расчет расходов государства на оказание амбулаторно-поликлинической помощи больным в связи с СД2 были включены визиты в поликлинику по месту жительства (88\%) либо в эндокринологический диспансер (8,4\%). В частном медицинском центре наблюдались 13 больных и 1 пациент у семейного врача. Большинство пациентов $(91,1 \%)$ обследуемой когорты получали первичную специализированную помощь у эндокринолога; 8,4\% больных по поводу СД2 лечились у терапевта. Основные характеристики оказания амбулаторной медицинской помощи больным СД2 в лечебно-профилактических учреждениях представлены в табл. 7.

Общее количество амбулаторных посещений специалистов составило 13534 в год, общая стоимость 4182563 руб., или 2077 руб. на 1 больного в год, включенного в исследование ФОРСАЙТ-СД2 (табл. 8).

4. Затраты на оказание стационарной помощи больным СД2 без учета осложнений (C4).

В затраты на оказание стационарной помощи больным СД2 были включены все случаи госпитализации, связанные с данной нозологией. За предшествующий год на стационарном лечении находились 1035 (51,4\%) пациентов изучаемой когорты.

Суммарная годовая стоимость госпитализации пациентов с СД2 без осложнений и сопутствующих заболеваний составила: 1035 чел. x 19 569,92 руб. = 20254871 руб., или 10057 руб. в год на 1 больного.

5. Затраты на оказание стационарной помощи больным СД2, имеющим хронические осложнения СД2 и сопутствующие заболевания (С5)

Прямые медицинские затраты на стационарное лечение осложнений СД2 и сопутствующих заболеваний составили 60203 рубля на 1 больного СД2 в год, или 5017 руб./мес. (табл. 9).

6. Частные (личные) затраты пачиентов на покупку лС и ИМН (Сб).

При проведении анкетирования пациентов 84\% больных, вошедших в исследование, ответили на вопрос об их средних ежемесячных личных расходах на покупку ЛС и ИМН. В результате расчетов средние затраты пациентов на ЛС и ИМН в амбулаторных условиях в 2014 г. составили 1688,4 руб./мес (от 0 до 30000 руб.), или 20261 руб./год.

Таким образом, общие прямые медицинские затраты на 1 пациента с СД2 в 2014 г. составили 105337 руб. на 1 пациента в год (табл. 10). Наибольшие затраты приходились на лечение осложнений и сопутствующих заболеваний - 57\%, расходные материалы 19\%, сахароснижающие препараты и инсулины - 10\%, госпитализации - 10\% в общей структуре прямых медицинских затрат.

Анализ прямых немедицинских затрат (DCn)

Прямые немедицинские затраты в связи с выплатами пособий по инвалидности на 1 год на 1 пациента в 2014 г. составили 24518 руб. на 1 пациента в год (в расчете на популяцию из 2014 больных в исследовании ФОРСАЙТ-СД2) (табл. 11).

\section{1. Анализ непрямых (косвенных) затрат (IC)}

Расчет недополученного ВВП вследствие временной нетрудоспособности (IC1):

- 443 человека пропустили работу по болезни (табл. 1);

- средняя длительность дней нетрудоспособности составила 20 дней (табл. 1);

- всего: 443 чел. $\times 20$ дней $\times 1342,81$ руб./сут= 11897276 руб./год, или 5907 руб./год/чел.

2. Расчет выплаты заработной платы по нетрудоспособности (IC2):

- 443 человека пропустили работу по болезни (табл. 1); - средняя длительность дней нетрудоспособности составила 20 дней (табл. 1);

- всего: 443 чел.×20 дней×1071,26 руб./сут=9 491396 руб./год, или 4712 руб./год/чел.

3. Расчет недополученного ВВП вследствие пропуска работы по нетрудоспособности у работающих инвалидов (IC3):

- составил 3080383 руб./год, или 1529 руб./год/чел. (табл. 12). 
Таблица 13. Общие непрямые (косвенные) затраты

Непрямые затрать

Недополученный ВВП вследствие временной нетрудоспособности

Выплаты заработной платы по нетрудоспособности

Недополученный ВВП вследствие пропуска работы по нетрудоспособности у работающих инвалидов

Потери ВВП, связанные с инвалидностью

ВСЕГО:
Сумма на когорту, руб. $(\mathrm{n}=2014)$

11897276

9491396

3080383

277139394

301608449

В среднем на 1 больного СД2, руб.

5907

4712

1529

137606

149754
Таблица 14. Общая стоимость сахарного диабета 2 типа в Российской Федерации, 2014 г.

\begin{tabular}{lcc}
\hline \multicolumn{1}{c}{ Виды затрат } & Сумма, руб. & $\%$ \\
\hline Прямые медицинские затраты & 105337 & 37,7 \\
Прямые немедицинские затраты & 24518 & 8,8 \\
Непрямые (косвенные) затраты & 149754 & 53,5 \\
\hline Общая стоимость СД2 & 279609 & 100 \\
\hline
\end{tabular}

\section{4. Расчет nотерь ВВП, связанных с инвалидностью} (IC4):

- 567 неработающих инвалидов (табл. 1) × 488782 руб. ВВП на душу населения = 277139394 руб. в год, или 137606 руб./год на 1 больного СД2.

Таким образом, общие непрямые (косвенные) затраты в 2014 г. в исследуемой группе больных составили 149754 руб./год/чел. (табл. 13).

\section{ОБСУЖДЕНИЕ}

С каждым годом все большее число людей в мире страдают СД2, который может привести к серьезным осложнениям, влияющим на качество жизни и ее продолжительность. Не менее важным на сегодняшний день является экономический аспект СД. В частности, по данным глобального систематического обзора, опубликованного в 2014 г. и посвященного анализу экономических затрат на лечение СД в различных странах с высоким, средним и низким уровнем дохода, установлено, что за последние 13 лет наблюдается стремительный рост экономического бремени СД2. В частности, затраты на лечение и экономические потери, связанные с нарушением трудоспособности, возрастают по мере тяжести осложнений и сопутствующих заболеваний. Авторы обзора утверждают, что ранние инвестиции, направленные на профилактику развития заболевания и своевременное начало медикаментозной терапии, являются наиболее эффективными мероприятиями по сдерживанию роста экономического и социального ущерба, наносимого СД2 [23].

Результаты клинико-экономических исследований свидетельствуют, что прямые затраты на оказание медицинской помощи больным СД будут увеличиваться с каждым годом. Так, по данным Американской диабетической ассоциации, в 2012 г. стоимость СД2 возросла на $41 \%$ за пять лет, а общие затраты на лечение СД2 в США в 2,3 раза превышают аналогичные показатели для лиц, не страдающих СД (13 700\$ на человека в год и 5800\$, соответственно) [24]. Основная часть расходов (около $3 / 4$ от всех затрат) связана с оплатой стационарного лече- ния, лечения осложнений заболевания, оказания помощи на дому и пребывания больных в хосписе, остальная $1 / 4$ часть расходов идет на оплату амбулаторного обследования и лечения, включающего затраты на сахароснижающую терапию. Следует отметить, что основная доля затрат на СД2 идет на медицинское обслуживание лиц пожилого возраста (59\%), имеющих большую длительность заболевания, и, в первую очередь, определяется распространенностью и тяжестью осложнений СД и сопутствующих сердечно-сосудистых заболеваний.

В 2016 г. в журнале «Сахарный диабет» были опубликованы данные расчета экономического ущерба от СД2, полученные в ходе международного многоцентрового эпидемиологического исследования International Diabetes Management Practices Study (IDMPS), спонсор «Санофи» (Франция), проведенного в РФ в 2012 г., в котором объем выборки больных СД2 составил 456 человек [8]. Анализ стоимости болезни включал расчет прямых медицинских, прямых немедицинских и непрямых затрат. В результате расчетов средние годовые прямые медицинские затраты на одного пациента с СД2 составили 52,1 тыс. руб., а с учетом непрямых затрат (8,7 тыс. руб.) и прямых немедицинских затрат (10,2 тыс. руб.) - 70,8 тыс. рублей [8].

Эти результаты согласуются с полученными данными в исследовании ФОРСАЙТ-СД2 - средняя годовая стоимость СД2 в России (СОI) составила 279609 руб. (по средневзвешенному курсу ЦБ РФ \$ США на 31 декабря 2014 г. 38,4183 руб./\$[22] - 7278\$) на 1 человека в год, из которых прямые медицинские затраты составили 105337 руб. (2742\$) (38\%), непрямые - 149754 руб. (3898 \$) (54\%) и прямые немедицинские - 24518 руб. (638\$) (9\%). В то же время прямое сравнение полученных результатов двух клинико-экономических исследований проводить затруднительно в связи в связи с отсутствием в исследовании DMPS детального анализа непрямых затрат с тем, что в исследовании IDMPS учитывался только ущерб ВВП из-за временной утраты трудоспособности (IC1) - 8,7 тыс. руб. в исследуемой когорте на одного пациента в год по сравнению 5,9 тыс. руб. в исследовании ФОРСАЙТ-СД2). Учет непрямых (косвенных) затрат государства в проведенном нами клинико-экономическом исследовании на выплату заработной платы по нетрудоспособности (IC2) - 4712 руб./год/чел., на недополученный ВВП вследствие пропуска работы по нетрудоспособности у работающих инвалидов (IC3) - 1529 руб./год/чел. и потерь ВВП, связанных с инвалидностью (IC4), - 137606 руб./год/чел. определил ведущую статью расходов на СД2.

При проведении дополнительных расчетов, основанных на результатах исследования IDMPS и результа- 
тах Российского эпидемиологического исследования NATION, было установлено, что затраты государства на СД2 в России в 2014 г. составили около 569 млрд руб. в год, при этом большую часть расходов (75\%) составляли непрямые затраты [25].

Прямые медицинские затраты, полученные в исследовании ФОРСАЙТ-СД2, составили 105337 руб./год/чел. (\$2742) и были сопоставимы с аналогичными показателями ряда зарубежных стран: в США (2013 г.) прямые затраты на 1 больного с СД2 составляли \$7888 [24], в Италии - €3660,8 (2012 г.) [26], в Южной Корее - \$1938,8 [27], в Германии -5262 € [28], в Испании в 2011 г. - €3110,1 [29]. Следует отметить, что прямые затраты на лечение больных СД2 по данным зарубежных источников в 2-4 раза превышают затраты на лечение больных, не страдающих данным заболеванием [24, 26, 27, 29].

В проведенном исследовании ФОРСАЙТ-СД2 анализ структуры прямых медицинских затрат показал, что большинство расходов (57\%) приходится на лечение осложнений СД2 и сопутствующих заболеваний (рис. 2). Наибольшие затраты приходятся на лечение диабетической полинейропатии (15,3\% всех затрат на лечение осложнений СД2), артериальной гипертензии - (14,2\%), нарушений сердечного ритма $(9,6 \%)$, диабетической ретинопатии (8,4\%).

Нами было установлено, что суммарные затраты на стационарное лечение составили 70260 руб. на 1 человека в год (66,7\% в структуре прямых медицинских затрат). В европейских странах доля расходов на стационарное лечение в структуре прямых медицинских затрат несколько меньше, чем в РФ, и составляет от 40 до 57\% [27, 30], в США - 43\% [23], в Израиле - 56\% [31]. Затраты на госпитализацию больного СД2 с наличием осложнений и сопутствующих заболеваний, установленные в исследовании ФОРСАЙТ-СД2 (60 203 руб. на 1 пациента), в 6 раз превышают затраты на госпитализацию больного без осложнений СД (10 057 руб. на 1 пациента).

гипотензивные и гиполипидемические препараты

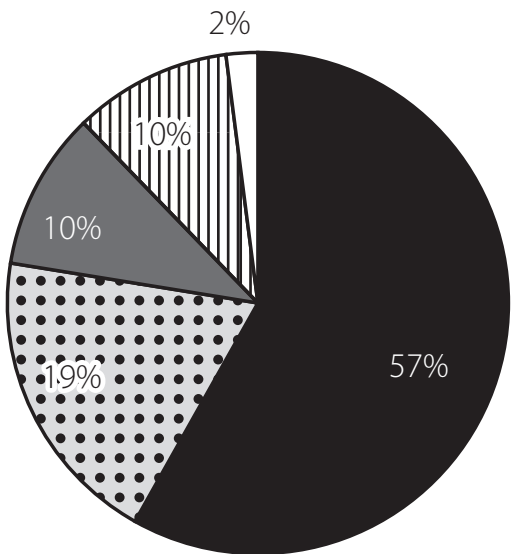

Лечение осложнений и сопутствующих заболеваний

• Расходные материалы

- Сахароснижающие препараты, инсулины

Ф Госпитализация при лечении СД2

\section{$\square$ Амбулаторно-поликлиническая помощь}

Рис. 2. Структура прямых медицинских затрат на сахарный диабет 2 типа в России по результатам исследования ФОРСАЙТ-СД2.
Полученные результаты расчетов совпадают с данными зарубежных отчетов о стоимости болезни: наличие осложнений увеличивает стоимость госпитализации в 2-5 раз (наибольшее влияние на увеличение затрат оказывает наличие микрососудистых осложнений и сердечно-сосудистых заболеваний) [25, 28, 32].

Затраты на сахароснижающую терапию в исследовании ФОРСАЙТ-СД2 составляют всего $10 \%$ от прямых медицинских расходов на лечение - 10228 руб. в год на 1 человека. Кроме того, почти все больные с артериальной гипертензией (62\% из 69,1\% с установленным диагнозом «артериальная гипертензия») получают гипотензивные препараты и лишь 17,8\% - гиполипидемические средства, что в среднем увеличивает прямые медицинские затраты всего на 2513 руб. в год на 1 пациента.

Лидирующие места в структуре затрат на сахароснижающую терапию занимают препараты инсулина (38\%), метформин (22,8\%), производные сульфонилмочевины (12,6\%) (рис. 3). Следует отметить, что у пациентов, получающих инсулин, прямые медицинские затраты оказались в 2,5 раза больше, чем у пациентов, получающих только ПССП [29].

Фармакоэпидемиологический анализ потребления ПССП выявил преимущественное использование низкозатратных групп сахароснижающих ЛС (59\% получали метформин, 4396 руб./год на 1 больного, 28\% - ПСМ 5126 руб./год), а на долю инновационных препаратов ингибиторов ДПП-4 в виде монотерапии или в виде фиксированной комбинации с метформином приходилось 8,2\%, средневзвешенная стоимость - 23727 руб./год и 30662 руб./год соответственно. Агонисты ГПП-1 получали лишь 0,5\% больных, что связано с их высокой стоимостью (149 504 руб./год на 1 человека для лираглутида).

Изучение терапевтического профиля потребления ЛС выявило еще одну существенную проблему лечения

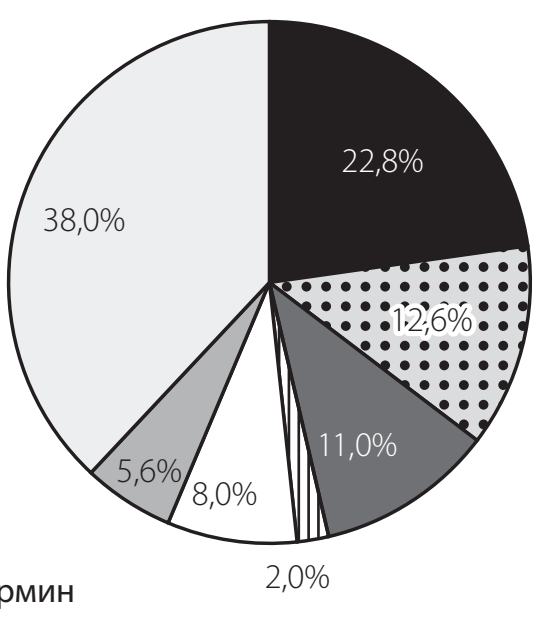

- Производные сульфонилмочевины (ПСМ)

Ингибиторы ДПП-4

Ш ПСМ + метформин

$\square$ Ингибиторы ДПП-4 + метформин

$\square$ Агонисты ГПП-1

$\square$ Инсулины

Рис. 3. Структура затрат на сахароснижающую терапию в России по результатам исследования ФОРСАЙТ-СД2. 
больных СД2 в нашей стране: несмотря на наличие большого числа больных с сопутствующими сердечно-сосудистыми заболеваниями, всего около 18\% обследованных получали гиполипидемическую терапию, при этом назначенная суточная доза (PDD) (для симвастатина 16 мг, для аторвастатина - 15 мг, для розувастатина 13 мг) была значительно ниже средних терапевтических доз, необходимых для достижения целевых значений липидного спектра. В то же время 98\% больных с артериальной гипертензией, вошедших в исследование, получали адекватную гипотензивную терапию.

В России и Великобритании непрямые (косвенные) затраты преобладают над прямыми, тогда как в других странах (Германии, Италии, Иране и др.) эти затраты примерно одинаковые. В США наблюдается значительное преобладание прямых медицинских затрат. Исходя из этих данных, можно предположить, что не только количество больных, выбранная терапия, частота госпитализаций и осложнений, но и уровень экономического благополучия страны, во многом определяющий бюджет системы здравоохранения, влияют на общую стоимость СД2.

\section{Ограничения исследования}

Настоящее исследование имеет определенные ограничения, свойственные для всех наблюдательных неинтервенционных исследований, связанные с его дизайном, что не исключает возможность систематических ошибок вследствие нерандомизированного дизайна и вероятности неполных или неточных данных.

\section{ЗАКЛЮЧЕНИЕ}

СД2 является не только глобальной медицинской, но и экономической проблемой для РФ. Большая часть затрат (53,5\%) на СД2 составляют потери ВВП вследствие нетрудоспособности больных СД. Прямые медицинские затраты составляют 37,7\% общей стоимости болезни, из которых 57\% приходится на лечение осложнений СД и сопутствующих заболеваний, тогда как на долю сахароснижающей терапии - всего 10\%.

В связи с тем, что больше половины всех прямых медицинских расходов приходится на лечение осложнений диабета, можно предположить, что увеличение затрат на раннюю диагностику заболевания и своевременное выявление осложнений СД2 и сопутствующих заболеваний, а также достижение терапевтических целей лечения у большего числа пациентов (целевых показателей гликемии, липидного спектра и артериального давления) будет способствовать снижению частоты развития и прогрессирования осложнений СД2, что приведет к снижению прямых немедицинских расходов и непрямых затрат государства, связанных с наличием СД2 в Российской Федерации.

\section{ДОПОЛНИТЕЛЬНАЯ ИНФОРМАЦИЯ}

Источник финансирования. Исследование выполнено в рамках проведения диссертационной работы, финансирование осуществлялось университетом за счет средств на утвержденные НИР.

Конфликт интересов. Авторы декларируют отсутствие явных и потенциальных конфликтов интересов, связанных с публикацией настоящей статьи.

Участие авторов. И.И. Дедов - научный руководитель проекта; М.Ф. Калашникова - главный координатор проекта - анализ результатов, написание текста, статистическая обработка данных, редактирование; Д.Ю. Белоусов, В.В. Рафальский, А.С. Колбин, В.В. Фадеев координаторы проекта - редактирование и финальное утверждение рукописи; А.Е. Чеберда, М.А. Кантемирова, В.Д. Закиев - статистическая обработка данных.

Благодарности. Авторы выражают искреннюю благодарность всем врачам-координаторам исследования и соисследователям за их добровольное участие в наблюдательном исследовании.

Рабочая группа врачей-координаторов и участников исследования: г. Москва: Н.В. Лиходей, М.А. Кантемирова, Е.И. Боброва, М.Г. Болотина, Е.Ю. Рашидова, М.Э. Тельнова, Л.В. Курманова; г. Санкт-Петербург: О.К. Хмельницкий; Московская область: А.П. Маликова, Э.Э. Юлдашева; г. Нальчик: Т.П. Таова, В.М. Терчокова, Ф.А. Таова, Ф.Н. Доттуева, А.С. Бекшокова, В.И. Чхетиани, Р.А. Мажгихова; г. Киров: Т.П. Веденская; г. Рубцовск: В.В. Корчинели; г. Барнаул: Н.В. Леонова; г. Назрань: А.М. Мержоева; г. Воронеж: Г.М. Панюшкина; г. Йошкар-Ола: Л.В. Егошина, Е.В. Фролова; г. Уфа: А.Ф. Гуфраева; г. Архангельск: И.В. Дворяшина; г. Всеволожск: Т.Ю. Воронцова, Ф.К. Хетагурова; г. Нижний Новгород: Н.А. Яркова, С.Д. Жук; г. Энгельс: Е.В. Жукова; г. Саратов: М.А. Куницына; г. Тюмень: С.А. Сметанина, О.Б. Макарова; г. Пенза: М.Ю. Сергеева-Кондратенко; г. Смоленск: А.В. Хайкина; г. Краснодар: Л.А. Иванова; г. Самара: М.В. Вербовая; г. Набережные-Челны: Г.С. Исхакова; г. Казань: Н.В. Куприянова; г. Новосибирск: И.А. Бондарь, О.Ю. Шабельникова, Т.М. Пилюгина, А.В. Пономаренко

\section{ПРИЛОЖЕНИЯ [SUPPLEMENTS]}

Приложения доступны на сайте журнала по URL: https://endojournals.ru/index.php/dia/article/view/9278

\section{ПРИЛОЖЕНИЕ 1}

Терапевтический профиль потребления таблетированных и неинсулиновых сахароснижающих лекарственных средств в натуральном и денежном выражении.

SUPPLEMENT 1

Therapeutic profile of consumption of oral and non-insulin hypoglycemic drugs in nonmonetary and in money terms.

URL: https://endojournals.ru/index.php/dia/article/downloadSuppFile/9278/2384

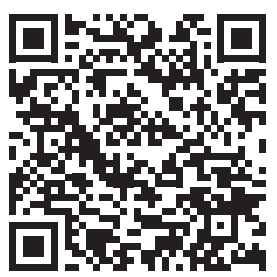




\section{ПРИЛОЖЕНИЕ 2}

Структура потребления инсулина и стоимость фармакотерапии в натуральном и денежном выражении.

SUPPLEMENT 2

The insulin consumption structure and pharmacotherapy cost in non-monetary and monetary terms.

URL: https://endojournals.ru/index.php/dia/article/downloadSuppFile/9278/2385

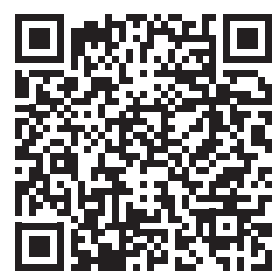

\section{ПРИЛОЖЕНИЕ 3}

Структура потребления гипотензивных ЛС и их стоимость в натуральном и денежном выражении.

SUPPLEMENT 3

The antihypertensive drugs consumption structure and their cost in non-monetary and monetary terms.

URL: https://endojournals.ru/index.php/dia/article/downloadSuppFile/9278/2386

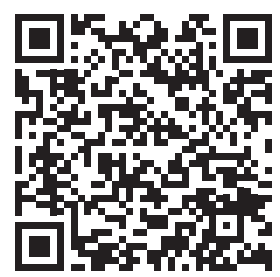

ПРИЛОЖЕНИЕ 4

Структура потребления гиполипидемических ЛС и их стоимость на 1 пациента в год в натуральном и денежном выражении.

SUPPLEMENT 4

The lipid-lowering drugs consumption structure and their cost per patient per year in nonmonetary and monetary terms.

URL: https://endojournals.ru/index.php/dia/article/downloadSuppFile/9278/2387

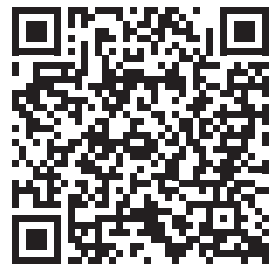

\section{СПИСОК ЛИТЕРАТУРЫ | REFERENCES}

1. IDF Diabetes Atlas, 7th edition. Brussels: International Diabetes Federation; 2015. Available from: http://www.diabetesatlas.org.

2. Global health risks: mortality and burden of disease attributable to selected major risks. Geneva: World Health Organization; 2009. Available from: http://www.who.int/healthinfo/global_burden_disease/ GlobalHealthRisks_report_full.pdf

3. Дедов И.И., Шестакова М.В., Викулова О.К. Государственный регистр сахарного диабета в Российской Федерации: статус 2014 г. и перспективы развития // Сахарный диабет. - 2015. T. 18. - №3 - C. 5-22. [Dedov II, Shestakova MV, Vikulova OK. National register of diabetes mellitus in Russian Federation. Diabetes mellitus. 2015;18(3):5-22. (In Russ.)] doi: 10.14341/DM201535-22

4. Дедов И.И., Шестакова М.В., Галстян Г.Р. Распространенность сахарного диабета 2 типа у взрослого населения России (исследование NATION) // Сахарный диабет. - 2016. - Т. 19. - № 2 C. 104-112. [Dedov II, Shestakova MV, Galstyan GR. The prevalence of type 2 diabetes mellitus in the adult population of Russia (NATION study). Diabetes Mellitus. 2016;19(2):104-112. (In Russ.)] doi: 10.14341/DM2004116-17

5. Centers for Disease Control and Prevention. National Diabetes Statistics Report, 2017. Atlanta: US Dept of Health \& Human Services, Centers for Disease Control and Prevention; 2017. Доступно: https:// www.cdc.gov/diabetes/pdfs/data/statistics/national-diabetes-statistics-report.pdf

6. Seuring T, Archangelidi O, Suhrcke M. The Economic Costs of Type 2 Diabetes: A Global Systematic Review. Pharmacoeconomics. 2015;33(8):811-831. doi: 10.1007/s40273-015-0268-9

7. Дедов И.И., Шестакова М.В., Сунцов Ю.И., и др. Результаты реализации подпрограммы «Сахарный диабет» Федеральной целевой программы «Предупреждение и борьба с социально значимыми заболеваниями 2007-2012 годы» // Сахарный диабет. - 2013. T. 16. - №2S. - C. 1-48. [Dedov II, Shestakova MV, Suntsov YI, et al. Federal targeted programme "Prevention and Management of Socially Significant Diseases (2007-2012)": results of the "Diabetes mellitus" sub-programme. Diabetes mellitus. 2013;16(2S):1-48. (In Russ.)] doi: 10.14341/20720351-3879

8. Дедов И.И., Омельяновский В.В., Шестакова М.В., и др. Сахарный диабет как экономическая проблема в Российской Федерации // Сахарный диабет. - 2016. - Т. 19. - №1. - C. 30-43. [Dedov II, Omelyanovskiy V, Shestakova MV, et al. Diabetes mellitus as an economic problem in Russian Federation. Diabetes mellitus. 2016;19(1):30-43. (In Russ.)] doi: 10.14341/DM7784
9. Дедов И.И., Калашникова М.Ф., Белоусов Д.Ю., и др. Фармакоэпидемиологические аспекты мониторинга здоровья пациентов с сахарным диабетом: результаты Российского наблюдательного многоцентрового исследования ФОРСАЙТ-СД 2 // Сахарный duaбem. - 2016. - T. 19. - №6. - C. 443-456. [Dedov II, Kalashnikova MF, Belousov DY, et al. Assessing routine healthcare pattern for type 2 diabetes mellitus in Russia: the results of pharmacoepidemiological study (FORSIGHT-DM2). Diabetes mellitus. 2016;19(6):443-456. (In Russ.)] doi: 10.14341/DM8146

10. Шамшурина Н.Г., Назаренко А.В., Шулятьев С.В. Сравнительный клинико-экономический анализ эффективности применения метода «кибернож» в онкологии // Здравоохранение. - 2015. - №7. C. 42-51. [Shamshurina NG, Nazarenko AV, Shuljat'ev SV. Sravnitel'nyj kliniko-jekonomicheskij analiz jeffektivnosti primenenija metoda «kibernozh» v onkologii. Zdravoohranenie. 2015;(7):42-51. (In Russ.)]

11. Омельяновский В.В., Авксентьева М.В., Сура М.В., и др. Методические рекомендации по оценке влияния на бюджет в рамках реализации программы государственных гарантий бесплатного оказания гражданам медицинской помощи. Утверждены приказом ФГБУ «ЦЭККМП» Минздрава России От «23» декабря 2016 г. [Omel'janovskij W, Avksent'eva MV, Sura MV, et al. Metodicheskie rekomendacii po ocenke vlijanija na bjudzhet v ramkah realizacii programmy gosudarstvennyh garantii besplatnogo okazanija grazhdanam medicinskor pomoshhi. Approved by order of Center for Healthcare Quality Assessment and Control 23 December 2016. (In Russ.)]

12. Guidelines for ATC classification and DDD assignment 2017. $20^{\text {th }}$ edition. Oslo: WHO Collaborating Centre for Drug Statistics Methodology. Norwegian Institute of Public Health; 2016. Available from: https://www.whocc.no/filearchive/publications/2017_guidelines_web.pdf

13. Официальный сайт Департамента здравоохранения г. Москвы [интернет]. Перечень предельных оптовых и розничных цен Ha 26.12.2014. [Official site of the Moscow Healthcare Department [Internet]. The list of the maximum wholesale and retail prices as of December 26, 2014. (in Russ.)] Доступно по: http://mosgorzdrav.ru/ ru-RU/citizens/health/drugs.html. Ссылка активна на 14.08.2017.

14. Информационный интернет-портал «Медицина для вас» [интернет]. Поиск лекарств в аптеках Москвы. [Information Internet portal «Medicine for you» [Internet]. Search for medicines in pharmacies in Moscow. (in Russ.)] Доступно по: http://www.medlux.ru. Ссылка активна на 14.08.2017 
15. Постановление Правительства РФ от 18 октября 2013 г. N 932 «О программе государственных гарантий бесплатного оказания гражданам медицинской помощи на 2014 год и на плановый период 2015 и 2016 годов». [Order of the Gouvernment of Russian Federation on 18 October 2013. N932 "O programme gosudarstvennykh garantiy besplatnogo okazaniya grazhdanam meditsinskoy pomoshchi na 2014 god i na planovyy period 2015 i 2016 godov". (In Russ.)] Доступно по: http://ivo.garant.ru/document?id=70379406\&byPara=1. Ссылка активна на 14.08.2017.

16. Приказ Федерального фонда ОМС от 14 ноября 2013 г. N 229 «Об утверждении «Методических рекомендаций по способам оплаты специализированной медицинской помощи в стационарных условиях и в дневных стационарах на основе групп заболеваний, в том числе клинико-статистических групп (КСГ) и клинико-профильных групп (КПГ) за счет средств системы обязательного медицинского страхования». [Order of the Federal Obligatory Medical Insurance Fund on 14 November 2013. N229 "Ob utverzhdenii "Metodicheskikh rekomendatsiy po sposobam oplaty spetsializirovannoy meditsinskoy pomoshchi v statsionarnykh usloviyakh i v dnevnykh statsionarakh na osnove grupp zabolevaniy, v tom chisle klinikostatisticheskikh grupp (KSG) i kliniko-profil'nykh grupp (KPG) za schet sredstv sistemy obyazatel'nogo meditsinskogo strakhovaniya". (In Russ.)] Доступно по: http://ivo.garant.ru/document?id=70418710\&byPara=1. Ссылка активна на 14.08.2017.

17. Progavrichenko.ru [интернет]. Размер социальной пенсии по инвалидности в 2014 году. [Progavrichenko.ru [Internet]. The size of the social disability pension in 2014. (In Russ.)] Доступно по: http:// progavrichenko.ru/lgoty-posobiya-pensii/razmer-pensij-po-invalidnosti-v-2014-godu.html. Ссылка активна на 14.08.2017.

18. Федеральный закон Российской Федерации №173-Ф3 от 17 декабря 2001 «О трудовых пенсиях в Российской Федерации (ред. от 03.12.2012)». [Federal Law of Russian Federation N173-FZ on 17 December 2001. «O trudovyh pensijah v Rossijskoj Federacii (ed on 03.12.2012)». (In Russ.)] Доступно по: http://www.consultant.ru/ document/cons_doc_LAW_34443. Ссылка активна на 14.08.2017.

19. Федеральная служба государственной статистики [Интернет]. Среднемесячная номинальная начисленная заработная плата работников в целом по экономике Российской Федерации в 1991-2017 гг. [Russian Federal State Statistics Service [Internet]. Average monthly nominal accrued wages of workers in the whole of the economy of the Russian Federation in 1991-2017. (in Russ.)] Доступно по: http://www.gks.ru/wps/wcm/connect/rosstat_main/ rosstat/ru/statistics/wages/. Ссылка активна на 01.06.2017 г.

20. Piepoli MF, Hoes AW, Agewall S, et al. 2016 European guidelines on cardiovascular disease prevention in clinical practice: The Sixth Joint Task Force of the European Society of Cardiology and other societies on cardiovascular disease prevention in clinical practice (constituted by representatives of 10 societies and by invited experts) developed with the special contribution of the European Association for Cardiovascular Prevention \& Rehabilitation (EACPR). Eur Heart J. 2016;37(29):2315-2381. doi: 10.1093/eurheartj/ehw106

21. Дедов И.И., Шестакова М.В., Майоров А.Ю., и др. Алгоритмы специализированной медицинской помощи больным сахарным диабетом / Под редакцией И.И. Дедова, М.В. Шестаковой, А.Ю. Майорова. - 8-й выпуск // Сахарный диабет. - 2017. -
T. 20. - №1S. - C. 1-121. [Dedov II, Shestakova MV, Mayorov AY, et al. Standards of specialized diabetes care. Edited by Dedov II, Shestakova MV, Mayorov AY. 8th edition. Diabetes mellitus. 2017;20(1S):1-121. (In Russ.)] doi: 10.14341/DM8146

22. Консультант Плюс [интернет]. Курс доллара и евро в 2014 году. [Consultant Plus [Internet]. The USD and the Euro in 2014. (in Russ.)] Доступно по: https://www.consultant.ru/law/ref/stavki/kurs-dollar-euro/ Ссылка активна на 01.06.2017 г.

23. $\mathrm{Ng}$ CS, Lee JY, Toh MP, Ko Y. Cost-of-illness studies of diabetes mellitus: A systematic review. Diabetes Res Clin Pract. 2014;105(2):151-163. doi: 10.1016/j.diabres.2014.03.020

24. American Diabetes Association. Economic costs of diabetes in the U.S. in 2012. Diabetes Care. 2013;36(4):1033-1046. doi: $10.2337 / \mathrm{dc} 12-2625$

25. Дедов И.И., Концевая А.В., Шестакова М.В., и др. Экономические затраты на сахарный диабет 2 типа и его основные сердечно-сосудистые осложнения в Российской Федерации // Сахарный дuaбem. - 2016. - T. 19. - №6. - C. 518-527. [Dedov II, Kontsevaya $A V$, Shestakova MV, et al. Economic evaluation of type 2 diabetes mellitus burden and its main cardiovascular complications in the Russian Federation. Diabetes mellitus. 2016;19(6):518-527. (In Russ.)] doi: 10.14341/DM8153

26. Bruno G, Picariello R, Petrelli A, et al. Direct costs in diabetic and non diabetic people: the population-based Turin study, Italy. Nutr Metab Cardiovasc Dis. 2012;22(8):684-690. doi: 10.1016/j.numecd.2011.04.007

27. Kim TH, Chun KH, Kim HJ, et al. Direct medical costs for patients with type 2 diabetes and related complications: a prospective cohort study based on the korean national diabetes program. J Korean Med Sci. 2012;27(8):876-882. doi: 10.3346/jkms.2012.27.8.876

28. Ulrich S, Holle R, Wacker M, et al. Cost burden of type 2 diabetes in Germany: results from the population-based KORA studies. BMJ Open. 2016;6(11):e012527. doi: 10.1136/ bmjopen-2016-012527

29. Mata-Cases M, Casajuana M, Franch-Nadal J, et al. Direct medical costs attributable to type 2 diabetes mellitus: a population-based study in Catalonia, Spain. Eur J Health Econ. 2016;17(8):1001-1010. doi: 10.1007/s10198-015-0742-5

30. Porath A, Fund N, Maor Y. Costs of managing patients with diabetes in a large health maintenance organization in Israel: a retrospective cohort study. Diabetes Ther. 2017;8(1):167-176. doi: 10.1007/s13300-016-0212-9

31. Williams R, Van Gaal L, Lucioni C; CODE-2 Advisory Board. Assessing the impact of complications on the costs of Type II diabetes. Diabetologia. 2002;45(7):13-17. doi: 10.1007/s00125-002-0859-9

32. Hex N, Bartlett C, Wright D, et al. Estimating the current and future costs of Type 1 and Type 2 diabetes in the UK, including direct health costs and indirect societal and productivity costs. Diabet Med. 2012;29(7):855-862. doi: 10.1111/j.1464-5491.2012.03698.x

33. Marcellusi A, Viti R, Mecozzi A, Mennini FS. The direct and indirect cost of diabetes in Italy: a prevalence probabilistic approach. Eur J Health Econ. 2016;17(2):139-147. doi: 10.1007/s10198-014-0660-y

34. Javanbakht M, Baradaran HR, Mashayekhi A, et al. Cost-of-illness analysis of type 2 diabetes mellitus in Iran. PLOS ONE. 2011;6(10):e26864. doi: 10.1371/journal.pone.0026864. 


\section{ИНФОРМАЦИЯ ОБ АВТОРАХ [AUTHORS INFO]}

Калашникова Марина Фёдоровна, к.м.н., доцент [Marina F. Kalashnikova, MD, PhD, associate professor]; aдpec: 119992, Москва, ул. Трубецкая, д. 8, стр. 2 [address: 8-2, Trubetskaya street, Moscow, 119992 Russian Federation]; eLibrary SPIN: 3777-4087; ORCID: http://orcid.org/0000-0002-7924-8687; e-mail: marina_kalash@mail.ru.

Дедов Иван Иванович, д.м.н., профессор, академик PAH [Ivan I. Dedov, MD, PhD, Professor]; eLibrary SPIN: 5873-2280; ORCID: http://orcid.org/0000-0002-8175-7886; e-mail: dedov@endocrincentr.ru.

Белоусов Дмитрий Юрьевич [Dmitriy Y. Belousov]; ORCID: http://orcid.org/0000-0002-2164-8290; eLibrary SPIN: 60679067; e-mail: clinvest@mail.ru.

Колбин Алексей Сергеевич, д.м.н., професcop [Aleksey S. Kolbin, MD, PhD, Professor];

ORCID: http://orcid.org/0000-0002-1919-2909; eLibrary SPIN: 7966-0845; e-mail: alex.kolbin@mail.ru.

Рафальский Владимир Витальевич, д.м.н., профессор [Vladimir V. Rafalskiy, MD, PhD, Professor]; ORCID: http://orcid.org/0000-0002- 2503-9580; eLibrary SPIN: 9424-2840; e-mail: v.rafalskiy@mail.ru.

Чеберда Алексей Евгеньевич [Aleksey E. Cheberda]; e-mail: aecheberda@healtheconomics.ru.

Кантемирова Мария Алексеевна [Mariya A. Kantemirova, MD]; ORCID: http://orcid.org/0000-0001-7425-8918; eLibrary SPIN: 1617-2644; e-mail: maria.kant@mail.ru.

Закиев Вадим Дмитриевич; [Vadim D. Zakiev]; ORCID: http://orcid.org/0000-0003-4027-3727; eLibrary SPIN 3631-6708; e-mail: endocrin1med@yandex.ru.

Фадеев Валентин Викторович, д.м.н., профессор, член-корр. PAH [Valentin V. Fadeev, MD, PhD, Professor]; ORCID: http://orcid.org/0000-0002-3026-6315; eLibrary SPIN: 6825-8417; e-mail: walfad@mail.ru.

\section{ЦИТИРОВАТЬ:}

Дедов И.И., Калашникова М.Ф., Белоусов Д.Ю., Колбин А.С., Рафальский В.В., Чеберда А.Е., Кантемирова М.А., Закиев В.Д., Фаеев В.В. Анализ стоимости болезни сахарного диабета 2 типа в Российской Федерации: результаты Российского многоцентрового наблюдательного фармакоэпидемиологического исследования ФОРСАЙТ-СД2 // Сахарный диабет. - 2017. — T. 20. — №6. — C. 403-419. doi: 10.14341/DM9278

\section{TO CITE THIS ARTICLE:}

Dedov II, Kalashnikova MF, Belousov DY, Kolbin AS, Rafalskiy VV, Cheberda AE, Kantemirova MA, Zakiev VD, Fadeyev VV. Cost-of-Illness Analysis of Type 2 Diabetes Mellitus in the Russian Federation: Results from Russian multicenter, observational, pharmacoepidemiologic study of diabetes care for patients with type 2 diabetes mellitus (FORSIGHT-T2DM). Diabetes mellitus. 2017;20(6):403-419. doi: 10.14341/DM9278 